\title{
O ATOR E O ESPETÁCULO NA GRÉCIA CLÁSSICA
}

\section{EDÉLCIO MOSTAÇO}

Conhecer em maior amplitude o universo do espetáculo na Grécia Antiga é uma importante fonte de inspiração e conduta para a prática teatral ainda hoje. Razão pela qual, foram aqui reunidas algumas considerações sobre o tema, resultante de informações recentes que, fundamentadas do ponto de vista arqueológico e filosófico, ajudam a colocar o conhecimento histórico em novos patamares. Iniciemos o exame pelos clássicos tratados de Aristóteles: a Poética e a Retórica. No estudo L'arte scenica degli attori tragici greci encontramos alguns esclarecimentos etimológicos sobre a condição do ator:

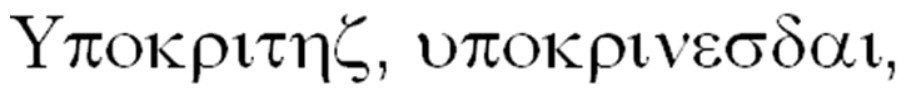

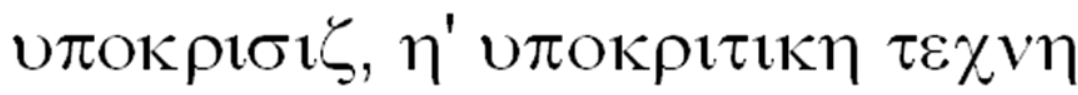

são os termos com que se indicava junto aos gregos a pessoa do ator, sua função, sua arte. E da raiz comum dessas supramencionadas expressões notaram os próprios antigos quer seu significado, quer seu próprio valor concordando, mesmo que, quando 
diálogo estabeleceu-se, ali se deveria perceber $\mathrm{o}$ ato de responder. Que hipokhrinesthai, com o significado de responder, era tarefa exclusiva do ator enquanto interlocutor com o coro, e não apenas do khoreutés, indica-o a expressão completa hipokhrinesthai tá iambeia: fórmula análoga de diathesthai, resim diapheranasthai; resin apotenai, eirai apotadên apneusti. Do significado originário passou-se a um mais amplo e geral, que é o do agir dramaticamente, como é o do hipokhrités e do próprio orkhestés, de modo que o termo hipokhrités passou para o vocábulo italiano [português] hipócrita, o sentido de pessoa que finge, já que toda a arte do ator está no fingimento. (CAPONE, 1935: 18-19).

Neste bem documentado estudo, a autora italiana destaca a precariedade dos materiais disponíveis para um estudo mais enfático da arte da representação na época; registrando, contudo, citações de comentaristas

(b) e testemunhos indiretos dando conta da existência de compêndios relativos à arte da mímica e da elocução, que não permitem saber, todavia, que indicações continham². A arte da elocução, contudo, foi alvo de preocupação nos tratados retóricos remanescentes, sendo que Aristóteles, na Retórica, anota sobre a ação oratória:

uma questão da mais alta importância e que ninguém ainda tratou: a que diz respeito à ação oratória. Com efeito só tardiamente penetrou ela no domínio da tragédia e da rapsódia, pois de início os poetas dramaturgos representavam eles próprios suas tragédias. É pois evidente que esta questão faz parte da arte retórica, como da arte poética. (...) Esta ação ocupa-se da voz, das diferentes maneiras de a empregar para expressar cada paixão: ora forte, ora fraca, ora média; estuda igualmente os diferentes tons que a voz pode assumir, alternadamente, aguda ou média, já que se ocupa do ritmo a ser utilizado em cada circunstância. Estas três coisas constituem o objeto de atenção dos oradores: a força da voz, a harmonia, o ritmo. Quem as possui, obtém geralmente o prêmio nos concursos públicos e, assim como no teatro, os atores presentemente levam a palma aos poetas, assim nas lutas 
políticas a ação oratória se reveste de maior importância que o próprio assunto por causa da imperfeição das constituições. Até esse dia não se compôs uma arte [técnica] sobre estas questões, pois que só tardiamente se começaram a estudar as regras da dicção (...), quando a ação é empregada produz o mesmo efeito que a representação do ator. (Retórica, III,13, 1 e seg)

O mais notório elemento do discurso retórico associado à arte do ator era a hipócrisis, a arte de falar estudada em detalhes na lexis ${ }^{3}$ (DUPONT-ROC/LALLO, 1980: 164176), uma das partes da tragédia, envolvendo não apenas a emissão vocal e suas peculiaridades fônicas (força "elocucionária", timbre, clareza, dicção e ritmo) como também conteudísticas (intencionalidade, sentido semântico, gestos e mímica que acompanham a emissão vocal, a postura corporal e o carisma, recursos associados à psicogogia, o conjunto de efeitos buscados com a finalidade de atingir o público). Uma vez que, "de que serviria um agente/personagem que fale, se a forma pretendida aparecesse sem a ação do intérprete das palavras?", pergunta Aristóteles na Poética, 1456b, 6.

Se a ação oratória produz-se mediante o correto emprego da arte do discurso, a interpretação do ator, todavia, requer outros atributos e possui traços distintivos que lhe são inerentes, bem percebidos pelo Estagirita:

a representação do ator depende de um dom natural e muito pouco da arte, ao passo que tudo quanto se refere ao estilo é verdadeiramente do domínio da arte (...). Como era natural, foram os poetas quem primeiro se ocuparam da questão, dado que as palavras são uma imitação/representação e a voz é, de todos os órgãos, o que melhor se presta para a imitação/representação. Daí procedem igualmente as técnicas: a do rapsodo, a do ator e outras . (...) o estilo oratório difere do poético. Os próprios acontecimentos mostram-no claramente, pois que os autores de tragédias deixam de utilizar esta maneira de se exprimir. (...) o iâmbico se aproxima mais do que os outros do discurso usual ( Retórica, 1386, 9.) 
O emprego de gestos, da mímica, de deslocamentos corporais conferia o necessário acabamento interpretativo, mesmo debaixo da máscara e da pesada indumentária utilizada pelos hipokhrités, compondo uma visualidade e um jogo de convenções cênicas que almejava o natural. $\mathrm{Na}$ concepção aristotélica, a naturalidade na representação era um alvo a ser buscado:

também, e na medida do possível, elaborar uma forma acabada recorrendo aos gestos: com efeito, em igualdade com os dons naturais, os mais persuasivos são os que movem violentamente as emoções, e aquele que está preso da agitação imita/ representa a agitação de modo mais verdadeiro; aquele que está preso da cólera imita/representa este arrebatamento de modo mais verdadeiro. (Poética, 1455a, 22.)

Quando notamos que o filósofo

(๑) recomendava ao poeta "compor os (-) fatos como se a eles estivesse presente, como se os tivesse sob os olhos", (1) tais observações, relacionadas à arte da interpretação, autorizam se afirmar que o ideal da mimese aristotélica é de cunho analógico, a busca de uma realização artística o mais próximo possível do natural, não apenas em sua acepção naturante (enquanto causa) como, especialmente, naturada (como resultado dado à vista); as duas faces correspondentes à dimensão interna e externa dos fenômenos que assim são "por natureza". Temos então um naturalismo, não apenas enquanto mimese de uma dimensão, mas em sua integralidade de fenômeno, já que aquele que está "preso [internamente] da agitação melhor a imita/representa [externamente]".

O Estagirita aqui bem destaca a relevância do espetáculo para a expressividade de uma emoção complexa ao articular, paulatinamente, uma cena que a vá construindo, mobilizando meios expressivos através de uma complexidade de recursos cuja finalidade é desembocar num dado resultado. É o que ocorre com a compaixão, por exemplo, uma das paixões a serem alcançadas na representação trágica: 
os males que parecem próximos excitam a compaixão (...); nestas condições acontece que necessariamente por meio de gestos, da voz, da indumentária e, em geral, da imitação/representação teatral, nos tornam mais acessíveis à compaixão; e por tais meios aproximam-nos da desgraça, futura ou passada, patenteando-a a nossos olhos, os acontecimentos recentes ou prestes a se produzirem são, por este motivo, mais próprios para provocar a compaixão. (Retórica, 1386a, 31.)

Se mais próprios, note-se, pertencem à ordem do conveniente, do persuasivo. Coisa que a sofística, desde algum tempo, vinha disseminando entre os atenienses, ela que trabalhou de modo especialmente ativo na articulação dos procedimentos suasórios; com ênfase para os ensinamentos de Górgias contidos em Helena. Dois testemunhos registram no Fedro de Platão e no De Oratore, III,32,128, de Cícero - a composição de um tratado de retórica da lavra de Trasímaco, exclusivamente dedicado à arte de comover os ânimos e os meios de excitar a compaixão, evidenciando que a arte do ator contava então, entre outros recursos, com esse decisivo implemento para fazer valer toda sua força cênica.

\section{A Cena Trágica}

Quatro eram as festas dedicadas ao deus da embriaguez em Atenas: as Dionisíacas da Cidade (ou Grandes Dionisíacas), realizadas na primavera do mês Elafebolion (março/abril), que irão sediar, depois de instituídos, os concursos dramáticos mais importantes; as Lenéias, dedicadas a Dioniso Leneu, a ocorrerem nos primeiros dias de janeiro, reunindo apenas a população de Atenas e com características apenas locais, com a duração de três ou quatro dias, onde outro concurso dramático será futuramente instituído; as Dionisíacas Campestres, durante o mês de dezembro, a mais antiga dessas comemorações em honra à divindade, território privilegiado do komos, um cortejo 
alegre e libidinoso, mesmo pornográfico e abusivo, onde os komastes entoavam canções fálicas e evoluíam guarnecidos de exagerados falos (eram os phallophores); e as Dionisíacas Antestéricas, celebradas durante três dias de fevereiro/março, as únicas que não comportavam manifestações abertas de espetáculos, deslocadas para o subúrbio de Argos e vinculadas a aspectos mais ritualísticos e próximos do mistério do deus.

As Grandes Dionisíacas ${ }^{4}$ representavam o ápice dessas comemorações, com a duração de seis dias, assim distribuídos: no primeiro, uma procissão mascarada, tendo à frente o arconte epônimo, transportava a imagem de Dioniso de seu templo até o teatro, instalando-a solenemente. Os sacerdotes da polis, os grupos organizados de efebos, homens, mulheres, visitantes e estrangeiros, integravam a grande comitiva seguida por algumas

(b) cabeças de bois que, sacrificados em (-) honra ao deus, a todos serviam de repasto. Os dois dias seguintes eram reservados ao concurso de ditiram- bos, instituído desde o fim do VI século. Era ele uma disputa entre as tribos atenienses, cada uma concorrendo com um coro e compositor próprios. No auge do $\mathrm{V}$ século contavam-se em Atenas dez coros ditirâmbicos: cinco de jovens com menos de 18 e cinco de homens entre 18 e 30 anos. Foi Péricles quem mandou construir o Odeon, um teatro específico para os ditirambos, já no final do século. Os três dias seguintes eram dedicados apenas às tragédias e, posteriormente, também às comédias. As representações iniciavam-se na parte da manhã, nessa fase mais complexa, quando as trilogias trágicas apresentavam-se e eram seguidas, após o almoço, de um drama satírico e uma comédia. A premiação dos vencedores dos diversos agons dava-se no último dia, quando os vencedores desfilavam em cortejo pela cidade e a imagem de Dioniso era reconduzida ao templo (NAVARRE, 1929: 101-105).

Apenas uma clareira de terra batida no sopé da Acrópole albergava o espetáculo em seus primórdios (prova- 
velmente a praça do mercado, onde os anfiteatros foram construídos em madeira), sendo que o edifício teatral em pedra, aos poucos, irá conhecer uma evolução e um aumento de dimensões, visando comportar as grandes multidões que afluíam a Atenas por ocasião das Grandes Dionisíacas. Instalado neste local de culto a Dioniso pelo komos e pelos devotos dos mistérios, a simples presença do teatro nesse local não autoriza, todavia, uma dedução linear sobre a origem da tragédia como tão somente um engrandecimento ou complexidade do ditirambo ali praticado. A tragédia, sob a forma como é conhecida nos textos que nos restaram, envolve uma somatória de componentes que se interpenetraram e se amalgamaram em modo ainda não muito claro. O ditirambo, sem dúvida, ocupa papel de destaque nessa gênese (como anotado no início da Poética), mas também contribuições da epopéia, das representações dos mistérios, do canto coral áulico e citaródico não devem ser descon- sideradas no nascedouro dessa complexa tessitura artística que é a poesia trágica. $^{5}$

Examinemos, então, o contexto onde o espetáculo ocorria.

Ao se tornarem prática consolidada, os concursos eram anuais. Cada poeta deveria, para deles participar, inscrever uma trilogia ou ao menos três peças com um mesmo tema e mais um drama satírico. O arconte epônimo era o responsável pela organização do concurso, pela escolha dos juizes e dos koregos, cidadãos ricos que arcariam com as despesas de apresentação das trilogias. Que não eram pequenas.

A função do korego iniciava-se bem antes da festa, com a contratação do coro (inicialmente cinqüenta cidadãos, diminuindo este número, com o passar do tempo, até um mínimo de quinze, na época de Eurípides), com o acerto de pagamento para os atores e as providências relativas a toda a infraestrutura cenotécnica, de figurinos, adereços e demais apetrechos indispensáveis à montagem (NAVARRE, 
1929: 111-143). E ela deveria ser dotada de brilho e elegância, para impressionar favoravelmente o júri, pois também eles disputavam concursos. Cada poeta e cada trilogia possuíam seu korego, o que aumentava a emulação entre eles. Deveriam estar inclusas ainda, no cômputo das despesas, as bebidas para os artistas e o público, além do farnel distribuído no horário da refeição. Uma coregia de tragédia foi avaliada em vinte e cinco minas e uma de comédia em quinze (correspondendo a mina, aproximadamente, a cem dias de salário de um operário não especializado). Ao entrar em declínio econômico, após a guerra do Pelo-poneso, Atenas teve dificuldades para continuar arcando com tais custos, incumbência que passou então a ser atribuída a alguns cidadãos ricos para, num momento seguinte, o próprio estado intervir com subvenções que viabilizassem a conti-

(๑) nuidade da atividade teatral.

Nessa fase a coregia já declinou e é a agonotesia, uma comissão designada pelo arconte, a responsável pela 74 amortização da empreitada que, em todos os tempos, foi considerada uma atividade da polis. Os espetáculos, em seu estágio inaugural, eram gratuitos para os cidadãos, que desfrutavam do theoricon. No século $\mathrm{V}$ a platéia foi estimada em mais ou menos 40 mil pessoas, para uma população de cerca de 400 mil habitantes, incluindo as circunvizinhanças da cidade. O público assim se dividia: na primeira fila sentavam-se os arcontes e magistrados, sendo a galeria distribuída por "classes": a nobreza agrária, os ginastas, os jovens, os comerciantes, sendo as mulheres deslocadas para as últimas filas. Péricles viu-se, com a crise, na contingência de cobrar o ingresso (equivalente, grosso modo, a um terço do salário diário de um operário), medida que causou confusões e revoltas, obrigando a intervenção do Estado, em 394, através de Êubolos, que passou a assumir o encargo, agora no valor de uma dracma, a diobolia.

Ao júri, inicialmente formado por dez cidadãos eleitos em sorteio, cabia selecionar os poetas que tivessem 
previamente se inscrito para o concurso, um para cada dia. Mas apenas cinco, dentre esses dez integrantes, escolhidos mediante um escrutínio secreto, deliberariam sobre o vencedor do agon. Coroado de louros, o poeta premiado era honrado com encômios diversos e efusivas homenagens, tendo seu feito lavrado em pedra para registro (a única fonte segura até hoje para estabelecimento da cronologia e títulos vencedores), figurando como um herói da cidade.

A koregia, o theoricon e o agon, eis as três instituições que garantiram, ao longo do tempo, a permanência da atividade teatral. ${ }^{6}$ Os textos dramáticos eram representados uma única vez (o que talvez seja uma explicação para seu quase total desaparecimento) e, raramente, eram dadas reposições ou efetivadas excursões às cidades próximas. ${ }^{7}$

Prática essa, entretanto, que se intensificará no século seguinte - não se sabe ao certo se em função da decadência de novos bons dramaturgos ou natural vontade de convívio com as grandes obras do passado, visto que também aumenta a circulação dos textos escritos (HAVELOCK, 1996 e THOMAS, 2005). Submetidos à censura e seleção prévia dos jurados, os textos eram escolhidos em função de certos valores e conveniências vigentes à época de suas apresentações. Não conhecemos nenhuma obra que não tenha participado de um agon. Tão estreitas vinculações entre o teatro e a polis jamais vieram a se repetir, no Ocidente, em outros contextos históricos. Prática ateniense por excelência, o teatro chegou a conhecer outros palcos, em outras cidades, mas nenhuma delas concedeu tanto espaço nem tanta ênfase a essa instituição verdadeiramente cívica na paideia helênica (MEYER: 1996).

\section{Recursos de Encenação}

O coro era ensaiado pelo corego; os atores, pelo poeta. Ésquilo criou a segunda figura em cena e Sófocles a terceira, chegando o autor de Prometeu a representar papéis em 
seus próprios textos. Tão diretas relações e afinidades entre os criadores da encenação podem explicar a pouca necessidade de didascálias nos textos, o que dificulta, na atualidade, uma visão mais clara dos modos de mise-en-scène vigentes na época. ${ }^{8}$

Além dos autores, igualmente os koregos e os hipokhrités entravam em concurso, o que contribuía para uma competição acirrada, vivamente comentada pela platéia. Como se observa no teatro de diversas outras culturas, notadamente orientais, apenas homens subiam ao palco, mesmo nos papéis femininos. Tal procedimento não obstaculizava a mimese almejada, porque o uso de máscaras impedia a visão dos rostos, e uma peruca alta, o onkós, encimava as cabeças, completando os trajes suntuosos e pesados, em geral em modelos próximos das roupas usuais, mas bem mais ricos e finamente adornados, confeccionados

(b) segundo certo padrão de cores que (1) facilitasse a identificação tipológica das figuras. A introdução dos koturnos, um (1) sapato de solado alto, é tardia, assim como dos ressonadores bucais para as máscaras, do final do século IV, provavelmente em função das dimensões crescentes dos teatros, favorecendo a visibilidade das últimas filas.

Os primitivos edifícios teatrais, erguidos em madeira, eram bastante simples: uma barraca, servindo de camarim para os atores, abrigava em sua face voltada para o público, alguns elementos cenográficos, lembrando um templo ou palácio, a skené. Uma plataforma de pouca altura, conhecida como proskenion, avançando à frente dessa barraca, tinha a função de palco para os atores. A orquestra, um grande círculo de terra batida onde evoluía o coro, era bem maior que essa plataforma. O público sentava-se no chão, aproveitando a encosta do terreno. Com as primeiras edificações em pedra a orquestra começa, paula-tinamente, a diminuir suas dimensões, enquanto tinham suas dimensões e complexidades aumentadas a skené e o theatron, a grande concha de escadarias na qual se alojava a platéia, formando um semicírculo. 
Uma máquina para fazer entrar e sair personagens mortos - a ekklikema - integrava os dispositivos cenotécnicos nesta fase mais evoluída; um segundo andar, por dentro da skené, era utilizado para o aparecimento de deuses (o theologeion); prismas triangulares, instalados em suas laterais, apoiavam panos pintados com cenas diversas (um bosque, um rio, o mar, numa tentativa de sugestão espacial), constituíam o periaktoi; deuses voavam instalados na mekané, um dispositivo móvel; além da existência de alçapões, rampas e escadas erigidas sobre o palco, permitindo maior desenvoltura nas movimentações de cena, dispositivos estes utilizados especialmente pelas comédias. O deus-ex-machina, uma espécie de cesta ou plataforma que descia do alto da skené, permitindo a aparição de algum deus ou entidade não humana, é invenção helenística (GRIMAL, 1986: 15-26).

Das formas simples e austeras do período arcaico até as sofisticadas soluções de sua época tardia, todo o aparato de materialização do teatro grego foi especializando e depurando suas técnicas cênicas, num sentido crescentemente "realista", em consonância com a temática dos textos que, aos poucos, vai abandonando as remotas situações míticas em benefício de situações e criaturas menos tensas, mais próximas emocional e existencialmente de sua platéia. As máscaras, não personalizadas e sem identificação, pesadas e quase sem expressões fisionômicas utilizadas nos estágios iniciais das representações vão, paulatinamente, incorporando vivacidade e movimento, num esforço de captação de tipos mais determinados para as figuras cênicas. ${ }^{9}$

A coréia implicava na dança, no canto e na música simultaneamente, ficando sob encargo do coro. A melopéia dizia respeito às canções entremeadas às representações e aos trechos falados, quando acompanhados ou sublinhados pelo som do aulus. As danças, majoritariamente executadas pelos coreutas, mas também pelos atores, poderiam, em momentos o- 
portunos, dar ensejo a passos orquésticos muito marcados, bem mais desenvolvidos nas comédias. Uma grande discussão sobre a dança utilizada na tragédia parece, apesar das muitas hipóteses já aventadas sobre o assunto, longe de estar terminada. Os gregos dançavam muito, sob muitas modalidades e circunstâncias, de modo que o apontamento de um gênero orquéstico específico para a tragédia ainda se constitui, a despeito das suposições, em enigma para os pesquisadores. $^{10}$

Sabe-se que o coro cantava e dançava simultaneamente, o que leva a crer que não poderia executar deslocamentos muito violentos ou rápidos. Há quem sustente, nesta hipótese, que apenas uma parte dele cantava, enquanto a outra dançava, recurso denominado hipokerma. De um modo ou de outro, a presença do coro e da dança era indispensável durante todo o

(๑) transcurso da tragédia (BOURCIER: 1987).

A comédia utilizava-se da

(1) kórdax, dança próxima da emélia, baseando seus passos em giros de quadril, o busto quebrado para a frente, em saltos rápidos e rodopios de corpo, onde a pantomina conhecia um destaque, alcançando forte colorido interpretativo. O drama satírico fazia uso da sikimnis, na qual os jogos pantomímicos se constituem em ingrediente indispensável, o que, juntamente com a caracterização dos sátiros, chegou a contribuir para que tais intervenções grupais configurassem quase um entreato, verdadeiros módulos de teor farsesco (BOURCIEU, 1987 e WOISEN, 1985).

Teatro ao ar livre, a skené não possuía cortina ou boca de cena. Ela surgirá no período helenístico, mas apenas para permitir rápidas trocas de cenários e não para vedar a cena da platéia, como veio a ocorrer, posteriormente, no teatro latino. De início três degraus, e em sua evolução uma pequena escadaria, interligavam $o$ palco com a orquestra, dando curso a movimentações variadas entre esses dois planos de ação.

O espetáculo comportava o 
párodos (entrada do coro, sempre pela esquerda, do lado do demos), alguns estásimos (partes recitativas pelos agentes/personagens), albergando, ainda, um ou dois entreatos para as evoluções do coro, concluindo com o exodus, a retirada coral, sempre pelo lado do Pireu. Tal divisão não era rígida, estruturando-se em função das necessidades do enredo apresentado.

Cada tragédia ocupava, em média, duas horas de representação. $O$ drama satírico, apresentado após o almoço, versava sobre um tema integrante das tragédias anteriormente apresentadas sem possuir, todavia, uma trama onde a hybris ou a harmatia constituíssem ingredientes relevantes, tampouco incluindo cenas de catástrofe ou sofrimento. Fixo para qualquer enredo, o coro de sátiros, vestido com chifres e rabos de bode, em evoluções agressivas e bem mais movimentadas que na tragédia, marcava de modo relevante tal gênero dramático. $O$ drama satírico como que aliviava as tensões provocadas pelo espetáculo matinal, servindo para unir a platéia que saía, após a triunfal retirada dos sátiros, em cortejo pela cidade, onde outras atrações aguardavam a população, na imensa festa que eram as Grandes Dionisíacas (ADRADOS, 1983 e CAPONE, 1935).

\section{A Melopéia}

A melopéia conforma toda a estrutura melódica e rítmica da tragédia, admitindo vários modos de manifestação: desde a música instrumental que acompanhava os trechos recitados, os cantos e danças do coro, assim como a enunciação cadenciada que sublinhava o texto versificado dos protagonistas. Ainda que a melopéia tenha sido erigida como uma parte qualitativa da tragédia, são pouquíssimas as referências que faz a ela Aristóteles na Poética, não apenas quanto a seu aspecto melódico e rítmico como também àquilo que tange ao canto e à enunciação, cf. 1447a, 22; 1448b, 20 e 1449b, 29. Aderida à lexis, a melopéia encontrava-se tão imbricada com a hipocrisis que o filósofo 
dispensou-se de tratá-la em separado. As informações que se seguem visam fornecer dados rele-vantes sobre suas características, melhor situando seus elementos nessas considerações sobre o espe-táculo.

Um único instrumento sustentava melodicamente a tragédia: o aulus, espécie de flauta ou clarineta formada por dois cones e dotada de palheta, produzindo um som inebriante, de timbre alto. $\mathrm{O}$ músico que o executava sentava-se em local de destaque, um pequeno altar de pedra localizado inicialmente no centro e posteriormente numa lateral da orquestra - sendo o primeiro artista a entrar em cena.

Ao longo de todo o livro VIII da Política, Aristóteles ocupou-se da música, seus efeitos e conveniências para a educação da cidade. Após registrar que pode ela possuir três usos principais (servir à educação, ao

(๑) relaxamento e à catarse), anota o (-) filósofo que:

esta predisposição a ser afetada pela música, tão intensa em certas pes- soas, existe em todas elas, e só difere para menos ou para mais - por exemplo, a compaixão, o temor e também o entusiasmo são manifestações dela; de fato, algumas pessoas são muito suscetíveis a estas formas de emoção, e sob a influência da música sagrada vemô-las, quando ouvem melodias que Ihes excitam a alma, lançadas num estado semelhante ao dos doentes que encontram um remédio capaz de livrá-los de seus males; a mesma sensação devem experimentar as pessoas sob a influência da compaixão e do temor e as outras pessoas emotivas em geral, na proporção em que são suscetíveis a tais emoções, e todas devem passar por uma catarse e ter uma sensação agradável de alívio; da mesma forma as melodias catárticas proporcionam um sentimento de prazer sadio aos homens. São estas as harmonias e melodias nas quais os executantes da música dramática devem ser convidados a competir. (Política, 1342b, 30.)

O trecho demanda alguns comentários: tanto a compaixão quanto o temor, duas das paixões a serem alcançadas pela tragédia, igualmente 
podem ser despertas através da mú- linha:

sica; que esta modalidade musical, originalmente utilizada no ambiente dos cultos sagrados, predispunha os ouvintes a um transporte emocional, "excitando-lhes a alma" e, com isso, propiciando a catarse de certas emoções, o que é considerado saudável e causa de uma sensação de alívio; que era este tipo de melodia que deveria ser empregada nos concursos dramáticos. Tal como já ocorrera com o espetáculo, também a melopéia foi despachada da Poética; e o que aqui se observa é que ela, embora detentora de uma larga e bem assentada tradição no contexto cultural grego, igualmente não mereceu considerações mais extensas.

As afirmações verificáveis na Política, de qualquer modo, ajudam a subsidiar e situar o horizonte de referências do Estagirita quanto ao uso da música na polis, fazendo vislumbrar onde estão depositadas suas significações subjacentes à Poética. Comentando a rejeição da flauta por Platão (considerada, na República, um instrumento perverso), Aristóteles sub-

na realidade, 0 modo frígio tem 0 mesmo efeito entre as harmonias que a flauta entre os instrumentos, pois ambos são excitantes e emocionantes. Isto é evidente na poesia, pois o delírio báquico e todas as emoções similares são acompanhadas principalmente pela flauta entre os instrumento. (Política, 1342b, 33.)

A flauta aparece ligada, em seu nascimento, à máscara de Gorgó. Ensina J-P. Vernant que "a arte da flauta - ao mesmo tempo o instrumento, a maneira de tocá-lo, a melodia que dele se extrai - foi 'inventada' por Atena para 'simular' os sons penetrantes e agudos que ouvira da boca das Górgonas e de suas serpentes. Assim é que ela criou, para imitá-las, o canto da flauta, 'que reúne todos os sons' " (VERNANT, 1988: 72).

Ao tocá-la, porém, inflando as bochechas nos esforços de respiração, foi advertida de que poderia perder sua plácida beleza. Rejeitou a deusa o instrumento, temendo ser uma vítima 
de seu monstruoso efeito. Contraposta à lira de seu irmão Apolo, que permite o exercício da fala enquanto é dedilhada, enunciando belos e sonoros poemas, a flauta foi tomada como o instrumento da desrazão, não adequada para acompanhar a inteligência. Rejeitada por Atena e Platão, também o será por Aristóteles: a flauta é uma viatura para os arroubos báquicos.

Instrumento associado ao transe, insufladora do orgiasmo, do delírio, dos ritos e danças de desvario e possessão, a flauta preterida pela divindade foi recolhida por Mársias, o principal sátiro que integrava a parúsia de Dioniso. Mas nem sempre a flauta estará, a partir desse episódio, acompanhando exclusivamente a sonoridade das bacantes de Brômio. Seus efeitos foram registrados, no Héracles de Eurípides, também entre as bacantes do Hades: onde o herói dos doze trabalhos, presa das víboras de cem

(•) cabeças que o ameaçam nas profunde- zas da terra, é tomado pela lyssa, o Pavor. "Durante a crise frenética na (d) qual o Pavor, como poder sobrenatural, apodera-se de Héracles, a música da flauta e o rosto do herói tomam igualmente a aparência medonha da máscara de Gorgó: 'horrível, horrível, é a música desta flauta', canta o coro" (VERNANT, 1988: 77).

Tais emanações sobrenaturais estavam presentes no imaginário da platéia quando o flautista, com seu aulus, concentrado e solene, subia ao altar para, com um sibilino acorde, invocar as potestades míticas e dar início à tragédia.

Segundo um bem documentado estudo, deduzido das tragédias remanescentes e através de uma acurada análise de suas estruturas poéticas, versos, rimas e formas de composição, a evolução musical conheceu, dentro da tragédia, quatro períodos bem configurados $^{11}$ :

1) em seu momento primitivo, o coro tudo domina, ocupando-se não apenas do canto, da dança e das partes declamadas, ainda num estágio embrionário de agentes/personagens, bailando em forma de círculo ritual em torno do altar de Dioniso. Consistiam os 
instrumentos musicais os tímbales, os tamborins e as flautas;

2) o segundo período é inaugurado com Téspis que, ao assumir a função de um agente, dá início propriamente ao diálogo com o coro, principiando um envolvimento dramático. $O$ diálogo, até então predominantemente lírico, alterna-se entre o protagonista, o corifeu e o coro, num embrião de representação, mas o canto coral permanece ainda o mais notório ingrediente de todo o conjunto. Mesmo com Ésquilo, a se depreender da estrutura de Prometeu e Suplicantes, os mais antigos textos conservados, essa situação não se mostra muito alterada. $\mathrm{O}$ uso de dois atores favorece, evidentemente, um progresso dramático, mas tais textos não deixam de evidenciar certo peso e rigidez nas longas recitações. Na Orestíada, porém, notáveis desenvolvimentos dramáticos podem ser observados sem que, nas partes corais, modificações muito importantes sejam registradas. As estrofes, a métrica geral, obedecem a asseme-lhado molde orquéstico, pro- fundamente lírico em seu espírito; há pouca movimentação e a catástrofe é bastante conhecida do público;

3) será com Sófocles que a tragédia conhecerá uma grande mutação: a criação do terceiro ator e a diminuição da participação do coro. Ainda que intervindo menos, o coro mostra-se ainda umbilicalmente ligado à ação, evidenciando, enquanto expressividade métrica, muitas semelhanças com os coros esquilianos, mas ensejando diferenças quantitativas. São mais vivas as interlocuções, havendo oposições entre um ou dois corifeus com o restante do coro. A monodia, não empregada em Ésquilo senão em raros casos, torna-se mais explorada em Sófocles, mas os cantos nos quais os agentes/personagens tomam parte são ainda compostos nos moldes antigos. $A$ música melódica, aquela destinada a carrear emoções, surge em passagens muito discretas.

O grande episódio de transformação da música grega está associado à fundação do Odeon, destinado especialmente à música e 
aos ditirambos e que conhecerá, após 444, espetáculos musicais instrumentais de cítara e siringe (ou flauta de Pã). Tal renovação rapidamente mudará a face da música grega, tornando-a mais marcadamente "imitativa"/melodiosa, introduzindo um novo gosto entre o público. Sófocles já estará muito velho para absorver tais modificações, preferindo referenciar-se pelos moldes do passado.

4) o quarto período será dominado por Eurípides, franco renovador da tragédia, em conformidade com a fermentação cultural sofística e as decorrências que a conquista macedônica haviam produzido na vida social de Atenas. Ainda que tenha lançado mão dos mitos tradicionais, Eurípides flagrou mais extensivamente os sentimentos que acometiam as criaturas no interior das situações, mas, com isso, houve quem o considerasse "melodramático", pouco trá-

(•) gico. Será ele quem introduzirá a nova música na tragédia, diminuindo as intervenções do coro nos diálogos e aumentando suas evoluções orqués- ticas. Tal dissipação de dramaticidade mostrar-se-á fortemente amparada numa estrutura musical mais melodiosa, imprimindo à sua produção certos arranjos internos que prefiguraram uma espécie de ópera renascentista, intercalando partes faladas e outras cantadas, como se fossem árias. Constitui-se tal expediente no triunfo da monodia, a mais importante renovação da tragédia nova. Foi o que teria levado Plutarco a declarar, no $D e$ Musica, que "os músicos antigos eram amantes dos ritmos, enquanto os modernos são amantes das melodias" (ESTEVE,1902: 22).

O antigo espírito trágico já não mais existe; a tragédia tornou-se imitativa, e tudo o que contrariou esta tendência, contra a qual ninguém soube reagir, foi destinada ao desaparecimento num tempo menos ou mais longo. Os novos cantos, ao contrário, afirmaram brilhantemente a importância do ator, favorecendo a tendência à interpretação; eles estavam em conformidade com o novo espírito trágico, inspiravam-se diretamente na música da moda e as reproduziam em cena, 
como visível no gosto de um poeta inovador como Eurípides que já não possuía, como seus predecessores, razões sérias para conservar as formas antigas: ele não teria feito tanta falta se não tivesse sacrificado todo 0 resto",

Conclui sua argumentação o musicólogo J. Esteve, anunciando um juízo musical sobre Eurípides que, do ponto de vista dramático, costuma exatamente ser expresso ao inverso.

Resta fixar uma derradeira observação referente à poesia, constituída, desde suas origens, de música e dança, conformando um todo expressivo que qualquer separação inevitavelmente desfigura. Tal entroncamento entre poesia, dança e música é inteiramente subsumida na Poética aristotélica (GRIMAL, 1986: 22). Desde a antiga epopéia e passando por todos os demais formatos da aulética, da citaródica e da lírica, a poesia grega era sobretudo voz e movimento (NESTLE, 1930: 15-95 e FINSLER, 1947: 9-22).

O termo pé, utilizado para

distinguir os diversos ritmos e acentos melódicos, está de modo íntimo associado à sua natureza essencialmente corpórea, ligado à dança, onde o pé - alto ou baixo - designa os tempos e acentos átonos e fortes da composição.

A tragédia adotava preferentemente o trímetro iâmbico para as partes faladas (kataloguê) e diversos metros líricos para os cantos corais; sendo as langorosas intervenções dos agentes/personagens expressas em tetrâmetros trocaicos (parakataloguê). As intervenções do corifeu costumavam observar a métrica anapéstica (UU__), quer para os cantos quer para as danças. Os cantos corais tanto poderiam envolver sua totalidade quanto solos, duetos ou tercetos (NAVARRE, 1929:162). Espetáculo essencialmente rítmico, a tragédia pulsava, do início ao fim, sua respiração organicamente apoiada sobre o canto e a dança. 